\title{
Prevalence and Factors Associated with Undernutrition among Adults with Major Depressive Disorder in Northwest Ethiopia
}

\author{
Edmialem Gezahegn, ${ }^{1}$ Melkie Edris, ${ }^{2}$ and Berihun Assefa Dachew ${ }^{3}$ \\ ${ }^{1}$ Psychiatric Clinic, University of Gondar Hospital, Gondar, Ethiopia \\ ${ }^{2}$ Departmpent of Human Nutrition, Institute of Public Health, University of Gondar, Gondar, Ethiopia \\ ${ }^{3}$ Department of Epidemiology and Biostatistics, Institute of Public Health, University of Gondar, Gondar, Ethiopia
}

Correspondence should be addressed to Berihun Assefa Dachew; berihunassefa21@gmail.com

Received 6 August 2016; Revised 15 October 2016; Accepted 30 October 2016

Academic Editor: Ulrich Schweiger

Copyright (C) 2016 Edmialem Gezahegn et al. This is an open access article distributed under the Creative Commons Attribution License, which permits unrestricted use, distribution, and reproduction in any medium, provided the original work is properly cited.

\begin{abstract}
Background. Undernutrition and major depressive disorder are frequently co-occurring. Patients with impaired mental health are strongly vulnerable to the risks of having involuntary weight loss or deficiency of essential nutrients. However, there is no study which assesses undernutrition among major depressive patients in Ethiopia. Method. A total of 422 clients were included in the study. Structured questionnaires and anthropometric measurements were used for collecting the data. Bivariate and multivariate logistic regression model was fitted to identify factors associated with undernutrition. Odds ratio with $95 \%$ confidence interval was computed to determine the level of significance. Results. The prevalence of undernutrition was 31.4\% [95\% CI: 27.2-36.0]. Being in a rural residence $[\mathrm{AOR}=1.84,95 \% \mathrm{CI}(1.18-2.85)]$, taking multiple medication [AOR $=1.77,95 \% \mathrm{CI}(1.03-3.05)]$, taking prescribed diet $[\mathrm{AOR}=1.90,95 \% \mathrm{CI}(1.06-3.41)]$, and current use of alcohol $[\mathrm{AOR}=2.96,95 \%$ CI (1.34-6.55)] were factors significantly associated with undernutrition among depressive patients. Conclusion. The prevalence of undernutrition among adults with major depressive disorder was found to be higher than the general population. Appropriate nutritional education and nutritional assessment are recommended during the course of major depressive disorder.
\end{abstract}

\section{Background}

Mental health problems account for $13 \%$ of the total burden of disease $[1,2]$. Malnutrition and major depressive disorder are common health problems $[3,4]$. According to World Health Organization (WHO) estimate, major depressive disorder is projected to become the leading cause of disability and the second leading contributor to the global burden of disease by the year 2020 and the impact of this burden of disease is thought to be worse in developing countries [5].

Malnutrition is a major public health problem in developing countries including Ethiopia. According to the 2011 Ethiopian Demographic and Health Survey, the prevalence of moderately/severely malnutrition among Ethiopian men aged $15-59$ years was $13.4 \%$ and the prevalence is $11.8 \%$ (women) and 17\% (men) in Amhara region where the study is conducted [6]. It is also the most important risk factor for the burden of many diseases like TB [7], pneumonia [8], visceral leishmaniasis [9], and mental disorders [10].

Malnutrition and major depressive disorder are frequently cooccurring among adults with their interrelated effects and exacerbate one another in a vicious cycle. In developed countries malnourished persons have a 55\% increased risk of major depression over time and depressed persons have a $58 \%$ increased risk of becoming malnutrition but far less known in developing country [11]. Moreover, impaired mental health is strongly vulnerable to the risks of being involuntary weight gain, weight loss, or deficiency of essential nutrients [12-14]. This is because of poor self-care, being unable to shop or prepare foods, poor balanced diet, and unhealthy lifestyle. In addition, loss of appetite, being unable to eat regularly, and energy expenditure contribute for this association $[4,13]$. 
The sociodemographic characteristics of the respondents (such as sex, age, race/ethnicity, education status, and area of residence), dieting for medical reasons, use of psychiatric medicines, use of alcohol, and use of substances were factors associated with nutritional status of adults with major depressive disorder $[12,15,16]$.

Although there are an abundance of research about the underlying conditions that ultimately lead to undernutrition and major depressive disorder individually, little is known about the burden of undernutrition among depressive patients in developing countries [17]. In Ethiopia, many studies have been conducted to identify the magnitude and consequence of undernutrition in different population groups. However, the issue of undernutrition was not well addressed among adults with major depressive disorder. Therefore, assessing the nutritional status of major depressive patients is crucial for identifying the multidimensional conditions where management requires a holistic approach by several methods of assessment and intervention, including nutritionrelated health indicators, dietary intake, and energy expenditure [15].

Thus, this study was able to disclose the prevalence and associated factors of undernutrition among adults with major depressive disorder at the University of Gondar Teaching Hospital and Bahir Dar Felege Hiwot Referral Hospital. The findings of this study will be useful for policy makers, program managers, and other concerned bodies to design appropriate strategies.

\section{Methods and Materials}

2.1. Study Design and Setting. Institutional based cross-sectional study design was conducted to determine prevalence of undernutrition and associated factors among adults with major depressive disorder. The study was conducted in psychiatry outpatient clinic at University of Gondar (UOG) Teaching Hospital and Bahir Dar Felege Hiwot Referral Hospital. University of Gondar teaching Hospital is located in Gondar town, $738 \mathrm{~km}$ way form Addis Ababa, capital city of Ethiopia, to Northwest direction and Felege Hiwot Referral Hospital is found in Bahir Dar town Ethiopia, the capital city of Amhara Regional State, and situated $565 \mathrm{Km}$ away from Addis Ababa to Northwest direction. Approximately, 8,000 adult patients per year have enrolled in chronic care from psychiatry outpatient clinics in both hospitals, of which, a total of 4500 patients per year with major depressive disorder (MDD) have been attending in both outpatient clinics $(2,500$ from UOG teaching hospital and 2,000 from Felege Hiwot Referral Hospital).

2.1.1. Source and Population. All psychiatry clinic outpatient adults with MDD who attend in the University of Gondar Teaching Hospital and Felege Hiwot Referral Hospital Bahir Dar were the source population for this study.

2.1.2. Inclusion and Exclusion Criteria. All adults with major depressive disorder were included, whereas pregnant and lactating women (<6 months) were excluded from the study.
2.1.3. Sample Size, Sampling Technique, and Sampling Procedures. The sample size of the study was calculated using the formula for the estimation of single proportion with the assumptions of $95 \%$ confidence interval $(z), 5 \%$ marginal error $(d)$, and taking proportion undernutrition among depressive patients as $50 \%$.

$$
\begin{aligned}
& n=\frac{z^{2}(p(1-P))}{d^{2}} \\
& n=\frac{1.96^{2}(0.5(1-0.5))}{0.05^{2}}=384 .
\end{aligned}
$$

With this assumption, the sample size becomes 384 . Considering 10\% nonresponse rate the final sample size becomes 422 . Proportional allocation is used to maintain proportionality among the two hospitals and then study participants from each hospital were selected by using systematic random sampling methods. Thus, 235 were from UOG Hospital and the rest 188 were from Bahir Dar Felege Hiwot Hospital.

2.2. Data Collection Instrument. Data were collected by using interviewer administered structured questionnaire and anthropometric measurements. The questionnaire contains sociodemographic characteristics, clinical factors, dietaryrelated factors, behavioral factors, and psychosocial factors. The questionnaires were prepared in English and then translated to Amharic (local language) and again back translated to English to check its consistency. Major depressive disorder and sleep disorder were diagnosed based on DSM-IV criteria [18]. Study subjects are considered as current use of alcohol or cigarette smoker, when they use specified substance at least once in the last three months and respondents who were taking $\geq 4$ types of medication per day were considered as taking multiple medications.

2.3. Anthropometric Measurements. A studio meter was used to measure the height of the study subjects. Each study subject was asked to stand on the surface, with weight distributed evenly on both feet, heels together against the studio meter, and the head positioned so that the line of vision was perpendicular to the body. The movable headboard was brought to the topmost point on the head with sufficient pressure to compress the hairs. The well-calibrated scale was used to weigh the study participants. To avoid the variability among the data collectors, the same measurement was employed for a given anthropometric measurement more than one time. Finally, BMI was calculated as $\mathrm{kg} / \mathrm{m}^{2}$ to determine the nutritional status of the respondents. A score less than 18.5 is considered as having undernutrition. It can be further classified as mild (17-18.4), moderate (16-16.9), and severe undernutrition $(<16)$.

2.4. Data Processing and Analysis. The data were coded and entered into Epi-Info version 7 and exported to SPSS version 20.0 software packages for analysis. Both descriptive and analytical statistical procedures were utilized. Binary logistic regression was used to identify factors associated with undernutrition among the depressive patients. Variables with a bivariate $P$ value $<0.20$ were further fitted into multivariate 
models for controlling the possible effect of confounders, and finally the variables that had significant association with depression were identified on the basis of odds ratio (OR), with $95 \%$ confidence interval $(\mathrm{CI})$ and $P$ value $(P<0.05)$. The variables were entered to the multivariate model using the Backward Stepwise (Likelihood Ratio) regression method. Model fitness was checked using Hosmer and Lemeshow goodness-of-fit test $(P=0.6)$. Multicollinearity was checked using variance inflation factor $(\mathrm{VIF}=1.5-2.5)$.

2.5. Ethical Considerations. Ethical clearance was obtained from Institutional Review Board (IRB) of the University of Gondar. Written informed consent was obtained from respondents who were selected to participate in the study.

\section{Results}

3.1. Sociodemographic Characteristics. A total of 405 respondents were included in the study with a response rate of $95.5 \%$. Among those 228 (56.3\%) were females. About 40\% of the respondents were married and $63 \%$ of the respondents were rural dwellers (Table 1).

3.2. Clinical Characteristics of Respondents. Nearly half 206 (50.9\%) of the respondents were under Amitriptyline medication. About $24 \%$ of the respondents were taking multiple (4 or more) medication per day.

From a total of 405 respondents only 98 (24.2\%) had known previous psychiatric disorder and 37 (9.1\%) of them had known previous medical disorders like TB, pneumonia, malaria, and acute gastritis. Two hundred and twelve (52.3\%) of the respondents had no sleep problem (Table 2).

3.3. Dietary and Behavioral Characteristics of Respondents. Among respondents 56 (13.8\%) of the participants were taking prescribed diet due to different medical reason in their dietary habit. The commonest food eaten by the majority $(76.6 \%)$ of the respondents was injera (Ethiopian traditional food).

Regarding to their behavioral characteristics 55 (13.6\%) participants used alcoholic beverages in the past three months and about $47 \%$ of them used greater than once per day (Table 3).

3.4. Prevalence of Undernutrition. The overall prevalence of undernutrition among adults with major depression disorder was 31.4\% [95\% CI: 27.2-36.0] and 23.7\% [95\% CI: 18.4-28.6] were mild, $4.7 \%$ [95\% CI: 1.6-7.8] were moderate, and 3.0\% [95\% CI: 1.2-4.3] were severe undernutrition cases.

3.5. Factors Associated with Undernutrition. In multivariate analysis, residence, multiple medication intake, taking prescribed diet, and current use of alcohol were significantly associated with undernutrition among patients with major depressive disorder.

Participants who live in rural areas were nearly two times more likely $[\mathrm{AOR}=1.84,95 \% \mathrm{CI}(1.18-2.85)]$ to have undernutrition as compared to participants who live in urban areas. On the other hand, participants who have used multiple medications per day were 1.70 times more likely $[\mathrm{AOR}=1.70$,
TABLE 1: Sociodemographic characteristics of adults with major depressive disorder (MDD) in University of Gondar and Felege Hiwot Referral Hospital $(n=405)$.

\begin{tabular}{|c|c|c|}
\hline Variables & Frequency & Percent \\
\hline \multicolumn{3}{|l|}{ Sex } \\
\hline Male & 177 & 43.7 \\
\hline Female & 228 & 56.3 \\
\hline \multicolumn{3}{|l|}{ Age in years } \\
\hline $18-26$ & 105 & 25.9 \\
\hline $27-35$ & 112 & 27.7 \\
\hline $36-45$ & 98 & 24.2 \\
\hline$>45$ & 90 & 22.2 \\
\hline \multicolumn{3}{|l|}{ Marital status } \\
\hline Married & 161 & 39.8 \\
\hline Single & 157 & 38.8 \\
\hline Separate/divorced & 60 & 14.8 \\
\hline Widowed & 27 & 6.7 \\
\hline \multicolumn{3}{|l|}{ Living condition } \\
\hline With family & 342 & 84.4 \\
\hline Alone & 63 & 15.4 \\
\hline \multicolumn{3}{|l|}{ Educational status } \\
\hline Cannot read and write & 107 & 26.4 \\
\hline Primary school & 129 & 31.9 \\
\hline Secondary school & 106 & 26.2 \\
\hline Higher education & 63 & 15.6 \\
\hline \multicolumn{3}{|l|}{ Occupation } \\
\hline No job & 126 & 31.1 \\
\hline Private employee & 93 & 23.0 \\
\hline Governmental employee & 56 & 13.8 \\
\hline Farmer & 52 & 12.8 \\
\hline Merchant & 51 & 12.6 \\
\hline Daily laborers & 27 & 6.7 \\
\hline \multicolumn{3}{|l|}{ Monthly income (USD) } \\
\hline$<50$ & 146 & 36.0 \\
\hline $50-100$ & 139 & 34.3 \\
\hline$>100$ & 120 & 29.6 \\
\hline \multicolumn{3}{|l|}{ Residence } \\
\hline Rural & 254 & 62.7 \\
\hline Urban & 151 & 37.3 \\
\hline
\end{tabular}

95\% CI (1.01-2.87)] to have undernutrition as compared to nonusers.

Participants who were not taking the prescribed diet due to medical reasons were nearly two times more likely to have undernutrition than those who had taken prescribed diet $[\mathrm{AOR}=1.90,95 \% \mathrm{CI}(1.06-3.41)]$. Moreover, participants who were using alcoholic beverages in the past three months were three times more likely to have undernutrition as compared to participants who had not used $[\mathrm{AOR}=2.96,95 \%$ CI $(1.34-$ 6.55)] (Table 4). 
TABLE 2: Clinical characteristics of respondents with major depressive disorder in University of Gondar Referral Teaching Hospital and Felege Hiwot Referral Hospital, Northwest Ethiopia, $2015(n=405)$.

\begin{tabular}{|c|c|c|}
\hline Variable & Frequency & Percent \\
\hline \multicolumn{3}{|l|}{ Length of treatment for MDD in month } \\
\hline$<3$ & 114 & 28.1 \\
\hline $3-8$ & 101 & 24.9 \\
\hline $9-27$ & 89 & 22.0 \\
\hline$>27$ & 101 & 24.9 \\
\hline \multicolumn{3}{|l|}{ Type of medication for MDD } \\
\hline Only amitriptyline & 206 & 50.9 \\
\hline Only fluoxetine & 146 & 36.0 \\
\hline Amitriptyline \& Chlorpromazine & 25 & 6.2 \\
\hline Fluoxetine \& Chlorpromazine & 14 & 3.5 \\
\hline Imipramine or others & 14 & 3.5 \\
\hline \multicolumn{3}{|l|}{ Food intake declined } \\
\hline Yes & 170 & 42 \\
\hline No & 230 & 58 \\
\hline \multicolumn{3}{|l|}{ Past psychiatric disorders } \\
\hline Yes & 98 & 24.2 \\
\hline No & 307 & 75.8 \\
\hline \multicolumn{3}{|l|}{ Known past medical disorders } \\
\hline Yes & 37 & 9.1 \\
\hline No & 368 & 90.9 \\
\hline \multicolumn{3}{|l|}{ Known current comorbidity } \\
\hline Yes & 30 & 7.2 \\
\hline No & 375 & 89.5 \\
\hline \multicolumn{3}{|l|}{ Under multiple medication } \\
\hline Yes & 99 & 24.4 \\
\hline No & 306 & 75.6 \\
\hline \multicolumn{3}{|l|}{ Sleep problem } \\
\hline Yes & 122 & 47.6 \\
\hline No & 212 & 52.3 \\
\hline
\end{tabular}

\section{Discussion}

The prevalence of undernutrition in this study was found to be $31.4 \%$ (95\% CI: 27.2-36.0). This finding is relatively high as compared to similar cross-sectional studies conducted in Taiwan [13], Portugal [19], and Bangladesh [20], in which 11\%, $12 \%$, and $26 \%$ of patients with major depressive disorder had undernutrition, respectively.

Moreover, this prevalence was also much higher than the previous study done in Iran (1.43\%) [21] and Boston (1.6\%) [22]. The difference might be due to socioeconomic difference, difference in dietary habits, and type of medication intake.

The findings of multivariate analysis revealed that the likelihood of being undernutrition was found to be higher among patients who come from rural area as compared to urban $[\mathrm{AOR}=1.84,95 \% \mathrm{CI}(1.18-2.85)]$. This finding was in line with the finding reported from Nepal [16]. This could be due to the fact that patients coming from rural area were engaged in high energy expending activities as compared to urban dwellers. Moreover, those study subjects from rural
TABLE 3: Individual characteristics related to dietary and behavioral characteristics of respondents with major depressive disorder in University of Gondar Referral Teaching Hospital and Felege Hiwot Referral Hospital, Northwest Ethiopia, $2015(n=405)$.

\begin{tabular}{|c|c|c|}
\hline Variable & Number & Percent \\
\hline \multicolumn{3}{|c|}{ Taking prescribed diet } \\
\hline Yes & 56 & 13.8 \\
\hline No & 349 & 86.2 \\
\hline \multicolumn{3}{|c|}{ Food commonly eaten } \\
\hline Injera & 311 & 76.6 \\
\hline Bread/Kita & 69 & 17 \\
\hline Qolo (cereals) & 25 & 6.2 \\
\hline \multicolumn{3}{|c|}{ Frequency of meal per day } \\
\hline Two times & 135 & 33.3 \\
\hline Three times & 241 & 59.5 \\
\hline Four times & 29 & 7.2 \\
\hline \multicolumn{3}{|l|}{ Taking breakfast } \\
\hline Yes & 253 & 62.5 \\
\hline No & 152 & 37.5 \\
\hline \multicolumn{3}{|c|}{ Fruit \& vegetable per day } \\
\hline Yes & 132 & 32.6 \\
\hline No & 273 & 67.4 \\
\hline \multicolumn{3}{|c|}{ Water or fluid intake/day } \\
\hline$<3$ litters & 282 & 69.9 \\
\hline $3-5$ litters & 95 & 23.5 \\
\hline$>5$ litters & 28 & 6.9 \\
\hline \multicolumn{3}{|l|}{ Current smoker } \\
\hline Yes & 33 & 14.6 \\
\hline No & 372 & 85.4 \\
\hline \multicolumn{3}{|c|}{ Current use of alcohol } \\
\hline Yes & 55 & 13.6 \\
\hline No & 350 & 86.4 \\
\hline \multicolumn{3}{|c|}{ Frequency alcohol use } \\
\hline Once per day & 21 & 38.2 \\
\hline$>1$ per day & 26 & 47.3 \\
\hline Once per week & 8 & 12.7 \\
\hline
\end{tabular}

area might not be aware of healthy eating due to poor educational status or might not get the required amount of diet due to low income [21].

The current study, respondents who took multiple medications ( $\geq 4$ medications per day) were 1.70 times more likely to have undernutrition as compared to those who had not. This finding is supported by the previous studies done in Portugal [19], Boston [22], and Taiwan [13]. This could be due to the fact that medical comorbid illnesses could be associated with increased side effects and treatment resistance related to metabolic dysfunction which in turn leads to undernutrition $[19,22]$.

Moreover, a depressive patient who was not taking prescribed diet was two times more likely to have undernutrition as compared to those who had taken prescribed diet. This could be due to the fact that patients who had not take prescribed diet might be prone to different diseases and highly 
TABLE 4: Bivariate and multivariate analysis of factors associated with undernutrition among adults with major depressive disorder at University of Gondar Referral Teaching Hospital \& Felege Hiwot Referral Hospital.

\begin{tabular}{|c|c|c|c|c|}
\hline \multirow{2}{*}{ Characteristics } & \multicolumn{2}{|c|}{ Undernutrition } & \multirow{2}{*}{ COR $(95 \%$ CI $)$} & \multirow{2}{*}{$\mathrm{AOR}(95 \%)$} \\
\hline & Yes & No & & \\
\hline \multicolumn{5}{|l|}{ Sex } \\
\hline Male & 62 & 115 & 1 & 1 \\
\hline Female & 65 & 163 & $1.35(0.89-2.06)$ & $1.42(0.92-2.21)$ \\
\hline \multicolumn{5}{|l|}{ Living condition } \\
\hline Alone & 25 & 38 & $0.65(0.37-1.13)$ & $0.76(0.40-1.44)$ \\
\hline With family & 102 & 240 & 1 & 1 \\
\hline \multicolumn{5}{|l|}{ Residence } \\
\hline Rural & 66 & 188 & $1.93(1.26-2.97)^{*}$ & $1.84(1.18-2.85)^{*}$ \\
\hline Urban & 61 & 90 & 1 & 1 \\
\hline \multicolumn{5}{|l|}{ Medication for MDD } \\
\hline Only amitriptyline & 63 & 143 & $0.66(0.33-1.32)$ & $0.87(0.41-1.88)$ \\
\hline Only fluoxetine & 52 & 94 & $0.53(0.26-1.10)$ & $0.60(0.28-1.31)$ \\
\hline Other & 12 & 41 & 1 & 1 \\
\hline \multicolumn{5}{|c|}{ Known comorbid disease } \\
\hline Yes & 6 & 24 & $1.91(0.76-4.76)$ & $1.51(0.50-4.57)$ \\
\hline No & 121 & 254 & 1 & 1 \\
\hline \multicolumn{5}{|c|}{ Taking multiple medication } \\
\hline Yes & 51 & 119 & $1.77(1.03-3.05)^{*}$ & $1.70(1.01-2.87)^{*}$ \\
\hline No & 76 & 159 & 1 & 1 \\
\hline \multicolumn{5}{|l|}{ Sleep problem } \\
\hline Yes & 53 & 140 & $1.19(0.96-2.59)$ & $1.5(0.78-2.50)$ \\
\hline No problem & 22 & 49 & 1 & 1 \\
\hline \multicolumn{5}{|l|}{ Taking prescribed diet } \\
\hline Yes & 25 & 31 & 1 & 1 \\
\hline No & 102 & 247 & $1.95(1.09-3.47)^{*}$ & $1.09(1.06-3.41)^{*}$ \\
\hline \multicolumn{5}{|l|}{ Alcohol use } \\
\hline Yes & 8 & 47 & $3.03(1.39-6.61)^{*}$ & $2,96(1.34-6.55)^{*}$ \\
\hline No & 119 & 231 & 1 & 1 \\
\hline
\end{tabular}

${ }^{*}$ Statistically significant at $P<0.05$.

predisposed to different comorbidities, which in turn leads to undernutrition [16].

In addition, current use of alcohol was significantly associated with undernutrition among depressive patients. Those participants who used alcoholic beverages were nearly 3 times more likely to have undernutrition as compared to participants who had not drunk in the past three months. This is due to the fact that alcohol use interferes with the absorption and storage micronutrients. In addition, alcohol irritates the gastrointestinal system; it increases acid secretion by the stomach which can injure the lining of the small intestine and interferes with the ability to absorb vital nutrients. Furthermore, alcohol is a toxin that has to be deactivated by the liver, during the detoxification process the body uses thiamin, zinc, and other important nutrients and this can deplete the investments of healthy metabolism and also cause low mood, irritability, and/or aggressive behavior as well as more serious and long-term mental health problems which further predispose to undernutrition $[4,23]$.

The cross-sectional nature of the study design does not show the temporal relationship. Moreover, recall bias and reporting bias are the potential limitations of this study. However, interviewers allowed sufficient time for adequate recall of long-term memory.

\section{Conclusion}

The prevalence of undernutrition was found to be high in this study. Residences, multiple medications, taking prescribed diet, and current use of alcohol were factors associated 
with undernutrition among depressive patients. Therefore, prevention as well as early detection and treatment of undernutrition is mandatory for patients with major depressive disorders with special emphasis among patients who come from a rural area and patient taking multiple medications. Furthermore, awareness creation on the prevention of alcohol use among depressive patient is also recommended.

\section{Abbreviations}

$\begin{array}{ll}\text { AOR: } & \text { Adjusted odds ratio } \\ \text { BMI: } & \text { Body mass index } \\ \text { COR: } & \text { Crude odds ratio } \\ \text { DSM-IV: } & \text { Diagnostic and Statistical Manual of } \\ & \text { Mental Disorders 4th edition } \\ \mathrm{Kg} / \mathrm{m}^{2}: & \text { Kilogram per meter square } \\ \mathrm{MDD}: & \text { Major depressive disorder } \\ \mathrm{OR}: & \text { Odds ratio } \\ \text { SPSS: } & \text { Statistical package for the social sciences } \\ \text { WHO: } & \text { World Health Organization. }\end{array}$

\section{Competing Interests}

The authors declare that they have no competing interests.

\section{Authors' Contributions}

Edmialem Gezahegn originated the idea and wrote the proposal, participated in data collection, analyzed the data, and drafted the paper. Edmialem Gezahegn, Melkie Edris, and Berihun Assefa Dachew approved the proposal and participated in data analysis. Berihun Assefa Dachew wrote the manuscript. All authors read and approved the final version of the manuscript.

\section{Acknowledgments}

The authors would like to acknowledge the University of Gondar for ethical clearance and providing financial support. The authors would also like to thank study participants, data collectors, and all staffs working at the University of Gondar and Bahir Dar Felege Hiwot Referral Hospital Psychiatric Clinic for their dedicated cooperation.

\section{References}

[1] B. Gelaye, S. Lemma, N. Deyassa et al., "Prevalence and correlates of mental distress among working adults in Ethiopia," Clinical Practice and Epidemiology in Mental Health, vol. 8, pp. 126-133, 2012.

[2] B. Gelaye, M. A. Williams, S. Lemma et al., "Validity of the patient health questionnaire-9 for depression screening and diagnosis in East Africa," Psychiatry Research, vol. 210, no. 2, pp. 653-661, 2013.

[3] L. Payahoo, Y. Khaje-Bishak, B. Pourghassem Gargari, M. B. Kabir-Alavi, and M. AsghariJafarabadi, "Assessment of nutritional and depression status in free-living elderly in Tabriz, Northwest Iran," Health Promotion Perspectives, vol. 3, no. 2, pp. 288-293, 2013.
[4] L. Harbottle, Healthy Eating and Depression. How Diet May Help Protect Your Mental Health, Mental Health Group of the British Dietetic Association, 2007.

[5] World Health Organization, Mental Health: New Understanding, New Hope, World Health Organization, Geneva, Switzerland, 2001.

[6] Central Statistical Agency, Ethiopia Demographic and Health Survey 2011, pp. 182-183, 2012.

[7] L. J. Podewils, T. Holtz, V. Riekstina et al., "Impact of malnutrition on clinical presentation, clinical course, and mortality in MDR-TB patients," Epidemiology and Infection, vol. 139, no. 1, pp. 113-120, 2011.

[8] A. S. Ginsburg, R. Izadnegahdar, J. A. Berkley, J. L. Walson, N. Rollins, and K. P. Klugman, "Undernutrition and pneumonia mortality," The Lancet Global Health, vol. 3, no. 12, pp. e735e736, 2015.

[9] G. Malafaia, "Protein-energy malnutrition as a risk factor for visceral leishmaniasis: a review," Parasite Immunology, vol. 31, no. 10, pp. 587-596, 2009.

[10] I. Naidoo, K. E. Charlton, T. M. Esterhuizen, and B. Cassim, "High risk of malnutrition associated with depressive symptoms in older South Africans living in KwaZulu-Natal, South Africa: a cross-sectional survey," Journal of Health, Population and Nutrition, vol. 33, article 19, 2015.

[11] F. S. Luppino, L. M. de Wit, P. F. Bouvy et al., "Overweight, obesity, and depression: a systematic review and meta-analysis of longitudinal studies," Archives of General Psychiatry, vol. 67, no. 3, pp. 220-229, 2010.

[12] A. Bilgiç, A. İbis, E. Tutal, S. Koç, S. Sezer, and N. Özdemir, "Association of nutritional status with depression and sleep disorders in elderly end stage renal disease patients-does chronic inflammation cause it all?" Turkish Nephrology, Dialysis and Transplantation Journal, vol. 21, no. 2, pp. 148-155, 2012.

[13] A. C. Tsai, Y.-T. Chou, and T.-L. Chang, "Usefulness of the Mini Nutritional Assessment (MNA) in predicting the nutritional status of people with mental disorders in Taiwan," Journal of Clinical Nursing, vol. 20, no. 3-4, pp. 341-350, 2011.

[14] J. A. Solomon, Z. Zukier, and M. J. Hamadeh, The Role of Nutrition in Mental Health: Depression, Nutrition and Depression, 2010.

[15] C. U. Onyike, R. M. Crum, H. B. Lee, C. G. Lyketsos, and W. W. Eaton, "Is obesity associated with major depression? Results from the third national health and nutrition examination survey," American Journal of Epidemiology, vol. 158, no. 12, pp. 11391147, 2003.

[16] Z. Vafaei, H. Mokhtari, Z. Sadooghi, R. Meamar, A. Chitsaz, and M. Moeini, "Malnutrition is associated with depression in rural elderly population," Journal of Research in Medical Sciences, vol. 18, supplement 1, pp. S15-S19, 2013.

[17] C. Hadley, A. Tegegn, F. Tessema, J. A. Cowan, M. Asefa, and S. Galea, "Food insecurity, stressful life events and symptoms of anxiety and depression in east Africa: evidence from the Gilgel Gibe growth and development study," Journal of Epidemiology and Community Health, vol. 62, no. 11, pp. 980-986, 2008.

[18] American Psychiatric Association, Diagnostic and Statistical Manual of Mental Disorders, DSM-IV, 4th edition, 2000.

[19] J. Correia and P. Ravasco, "Weight changes in Portuguese patients with depression: which factors are involved?" Nutrition Journal, vol. 13, article 117, 2014.

[20] T. Ferdous, Z. N. Kabir, Å. Wahlin, K. Streatfield, and T. Cederholm, "The multidimensional background of malnutrition 
among rural older individuals in Bangladesh - a challenge for the Millennium Development Goal," Public Health Nutrition, vol. 12, no. 12, pp. 2270-2278, 2009.

[21] B. Pourghassem Gargari, M. Saboktakin, S. Mahboob, and N. Pourafkari, "Nutritional status in patients with major depressive disorders: a pilot study in Tabriz, Iran," Health Promotion Perspectives, vol. 2, no. 2, pp. 145-152, 2012.

[22] M. S. P. Toups, A. K. Myers, S. R. Wisniewski et al., "Relationship between obesity and depression: characteristics and treatment outcomes with antidepressant medication," Psychosomatic Medicine, vol. 75, no. 9, pp. 863-872, 2013.

[23] C. S. Lieber and N. Spritz, "Effects of prolonged ethanol intake in man: role of dietary adipose, and endogenously synthesized fatty acids in the pathogenesis of the alcoholic fatty liver," Journal of Clinical Investigation, vol. 45, no. 9, pp. 1400-1411, 1966. 


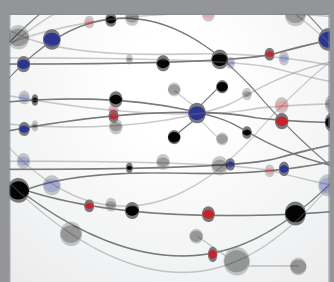

The Scientific World Journal
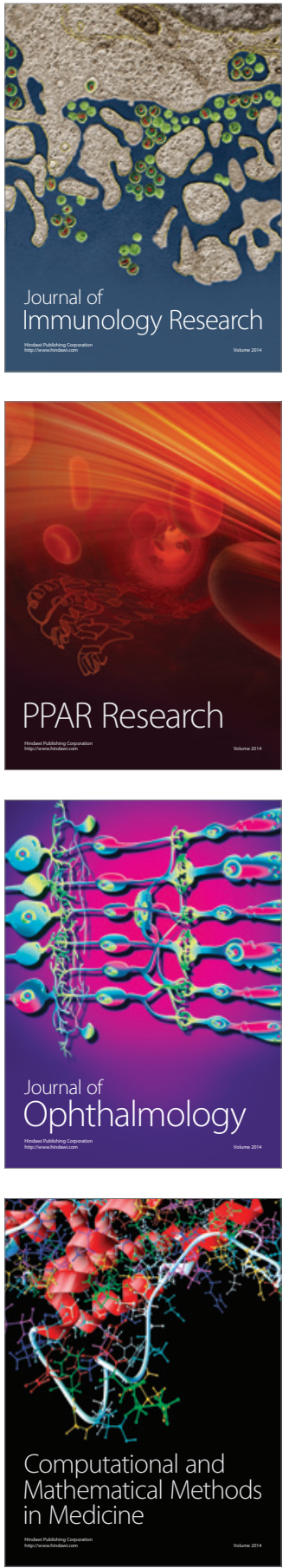

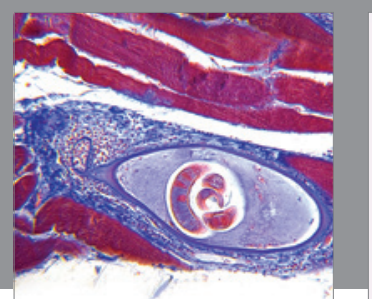

Gastroenterology Research and Practice

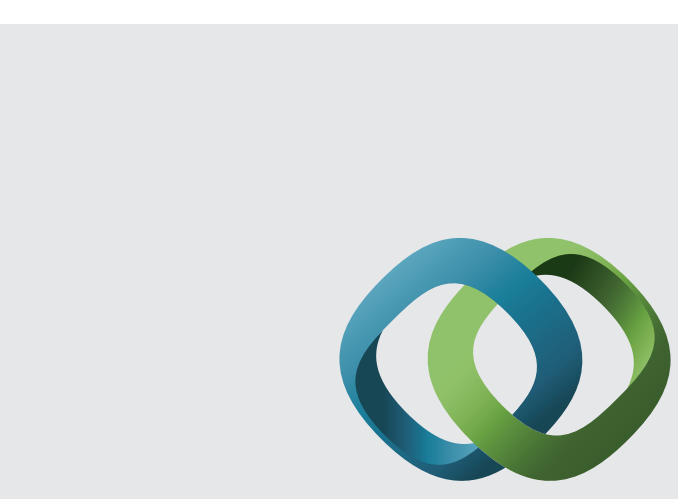

\section{Hindawi}

Submit your manuscripts at

http://www.hindawi.com
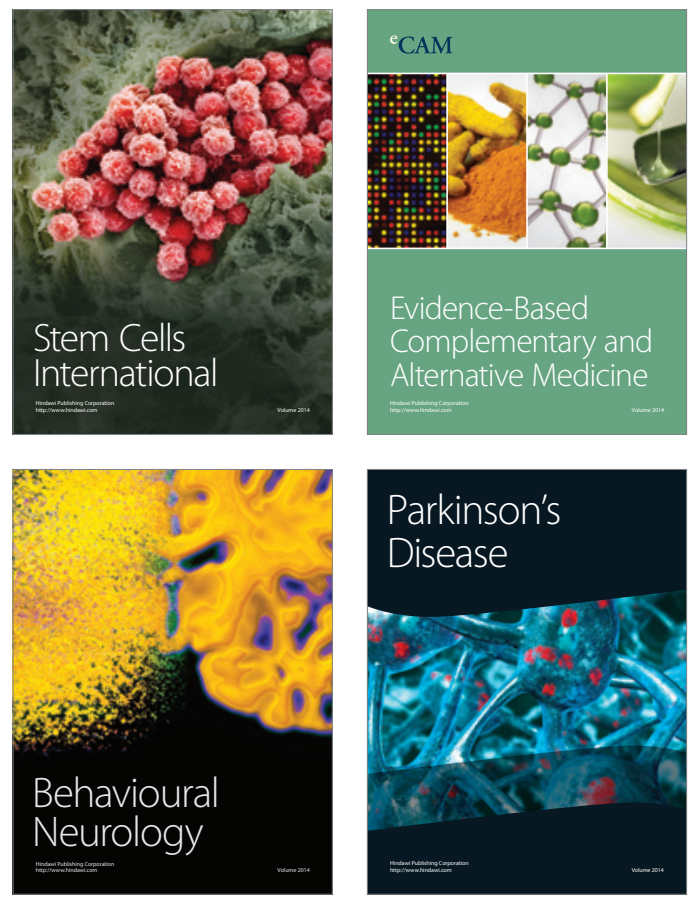
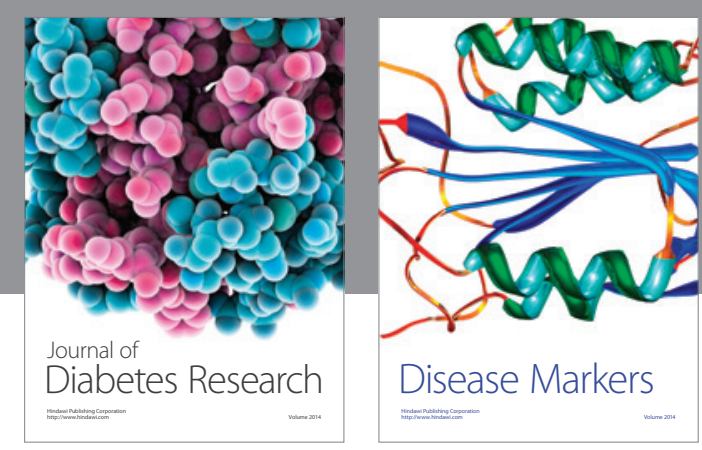

Disease Markers
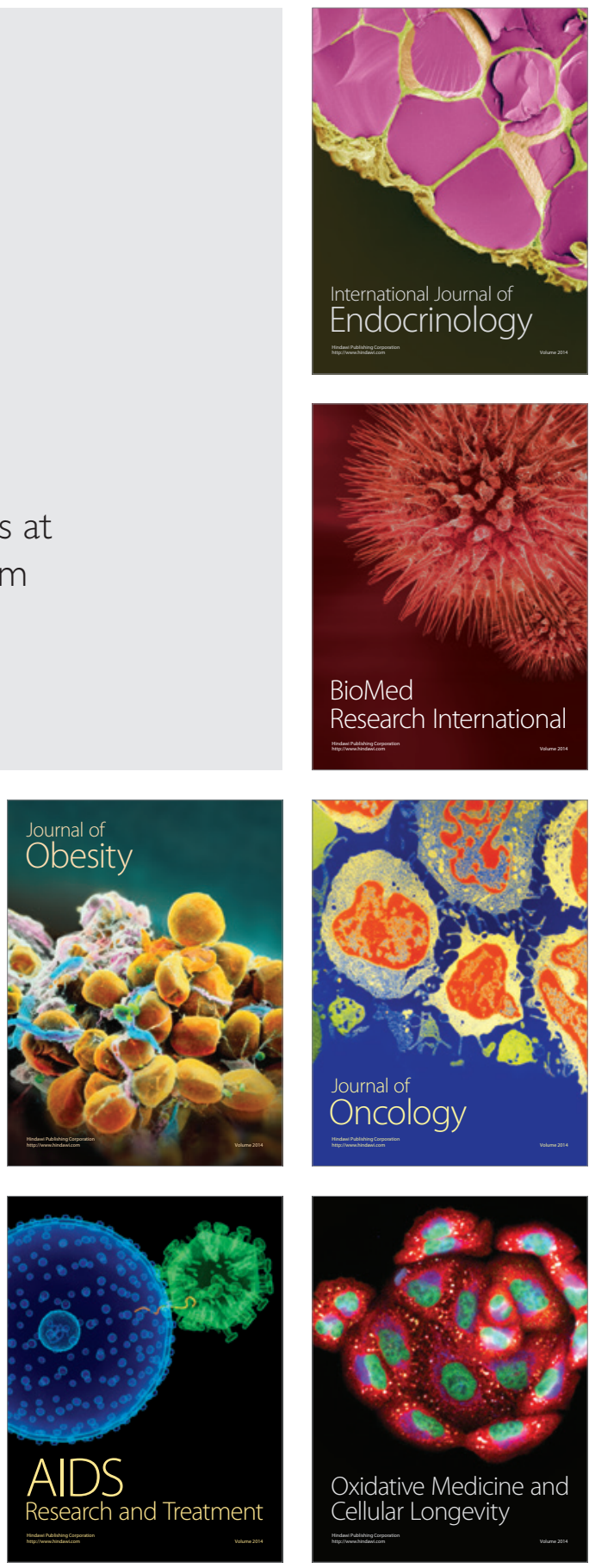